\title{
Combustion Synthesis of Large Bulk Nanostructured $\mathrm{Ni}_{65} \mathrm{Al}_{21} \mathrm{Cr}_{14}$ Alloy
}

\author{
Jiqiang Ma, ${ }^{1,2}$ Jun Yang, ${ }^{1}$ Qinling Bi, ${ }^{1}$ Licai Fu, ${ }^{1}$ Yonghai Kang, ${ }^{1,2}$ and Weimin Liu ${ }^{1}$ \\ ${ }^{1}$ State Key Laboratory of Solid Lubrication, Lanzhou Institute of Chemical Physics, Chinese Academy of Sciences, \\ Lanzhou 730000, China \\ ${ }^{2}$ Graduate University of Chinese Academy of Sciences, Beijing 100039, China
}

Correspondence should be addressed to Jun Yang, jyang@lzb.ac.cn

Received 11 January 2011; Accepted 17 February 2011

Academic Editor: Zhi Li Xiao

Copyright (C) 2011 Jiqiang Ma et al. This is an open access article distributed under the Creative Commons Attribution License, which permits unrestricted use, distribution, and reproduction in any medium, provided the original work is properly cited.

\begin{abstract}
A large bulk nanostructured $\mathrm{Ni}_{65} \mathrm{Al}_{21} \mathrm{Cr}_{14}$ alloy with dimensions of $\Phi 100 \mathrm{~mm} \times 6 \mathrm{~mm}$ was produced by combustion synthesis technique followed with rapid solidification. The $\mathrm{Ni}_{65} \mathrm{Al}_{21} \mathrm{Cr}_{14}$ alloy was composed of $\gamma^{\prime}-\mathrm{Ni}{ }_{3} \mathrm{Al} / \gamma-\mathrm{Ni}$ (Al, Cr) eutectic matrix and $\gamma$ - Ni(Al, Cr) dendrite. The eutectic matrix consisted of $80-150 \mathrm{~nm}$ cuboidal $\gamma^{\prime}-\mathrm{Ni}_{3} \mathrm{Al}$ and $2-5 \mathrm{~nm} \gamma$ - Ni(Al, Cr) boundary. The dentrite was comprised of high-density growth twins with about 3-20 nm in width. The nanostructured $\mathrm{Ni}_{65} \mathrm{Al}_{21} \mathrm{Cr}_{14}$ alloy exhibited simultaneously high fracture strength of $2200 \mathrm{MPa}$ and good ductility of $26 \%$ in compression test.
\end{abstract}

\section{Introduction}

Nanostructured materials exhibited enhanced strength, hardness, ductility at low temperature, wear-resistance, and other unusual properties in comparison with corresponding coarse counterparts [1-5]. Nanostructured materials can be produced by several methods, including consolidation of nanopowder by pressing and sintering, electrodeposition, devitrification of amorphous, and severe plastic deformation $[6,7]$. However, bulk nanostructured materials obtained by the above methods often suffer from porosity, contamination, weak bonding, and small dimensions. Furthermore, extortionate equipment and enormous energy have to be used in the above methods usually. Specially, the size of the prepared nanostructured materials is very limited. Consequently, it is of great interest to develop new processes that are convenient, low in cost, and capable of being scaled up for tailoring the nanostructured materials. Because the process is inexpensive and can obtain large bulk materials with good mechanical properties [8-13], combustion synthesis (CS) could become a promising method to produce bulk nanostructured materials.

Nickel-aluminium-based intermetallic compounds have been extensively studied because of their high melting points, relatively low densities, high strength, as well as good corrosion and oxidation resistances [14-21]. The chromium alloying not only plays a solid solution strengthening role for the $\gamma$-Ni matrix and $\gamma^{\prime}$ precipitates but also improves corrosion and oxidation resistances by creating a native, adherent oxide film [21, 22]. Moreover, the chromium alloying can also reduce brittleness at temperatures of $600-800^{\circ} \mathrm{C}$ in oxidizing atmosphere [23].

In this study, a bulk nanostructured $\mathrm{Ni}_{65} \mathrm{Al}_{21} \mathrm{Cr}_{14}$ alloy has been synthesized successfully by CS technique associated with rapid solidification by designing an aluminothermic reaction route. The obtained bulk nanostructured $\mathrm{Ni}_{65} \mathrm{Al}_{21} \mathrm{Cr}_{14}$ alloy exhibits simultaneously high strength and large ductility.

\section{Experimental}

Nickel, aluminum, chromium sesquioxide, and chromium trioxide powders were weighed according to the stoichiometry of the aluminothermic reaction (1) which is characterized by releasing a large amount of exothermic heat. The powders were dry-mixed for 8 hours with $\mathrm{Al}_{2} \mathrm{O}_{3}$ spheres in a stainless steel jar, and then $800 \mathrm{~g}$ of the mixed powders were cold-pressed on a copper substrate which was $170 \mathrm{~mm}$ in the diameter and fixed in a copper tube as a mold under 


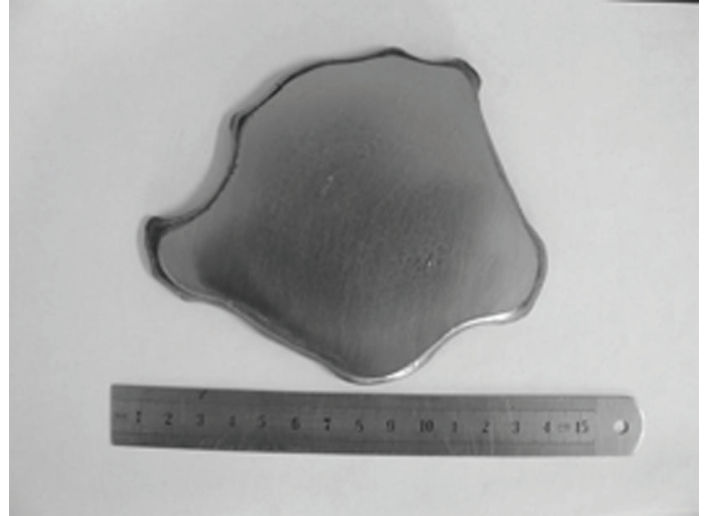

FIGURE 1: Photograph of the as-produced $\mathrm{Ni}_{65} \mathrm{Al}_{21} \mathrm{Cr}_{14}$ alloy sample.

TABLE 1: Properties of the raw material powders.

\begin{tabular}{lccc}
\hline Powder & Size (mesh) & Purity (wt.\%) & Impurity \\
\hline $\mathrm{Ni}$ & 200 & $>99.5$ & $\mathrm{Zn}, \mathrm{Pb}, \mathrm{Mn}, \mathrm{Si}$ \\
$\mathrm{Al}$ & $100-200$ & $>99$ & $\mathrm{Fe}, \mathrm{Si}, \mathrm{Cu}, \mathrm{H}{ }_{2} \mathrm{O}$ \\
$\mathrm{CrO}_{3}$ & - & $>99$ & $\mathrm{Cl}^{-}, \mathrm{SO}_{4}{ }^{2-}, \mathrm{Na}, \mathrm{Al}, \mathrm{Fe}$ \\
$\mathrm{Cr}_{2} \mathrm{O}_{3}$ & - & $>99$ & $\mathrm{Cl}^{-}, \mathrm{SO}_{4}{ }^{2-}, \mathrm{Fe}$ \\
\hline
\end{tabular}

a uniaxial pressure of $30 \mathrm{MPa}$. The substrate and tube were cleaned by ethanol before use. Characteristics of the reactant powders are given in Table 1.

$$
\begin{gathered}
10 \mathrm{CrO}_{3}+2 \mathrm{Cr}_{2} \mathrm{O}_{3}+45 \mathrm{Al}+65 \mathrm{Ni} \\
=\mathrm{Ni}_{65} \mathrm{Al}_{21} \mathrm{Cr}_{14}+12 \mathrm{Al}_{2} \mathrm{O}_{3} .
\end{gathered}
$$

Five grams of $\mathrm{Al}, \mathrm{S}$, and $\mathrm{MnO}_{2}$ powder mixture in mass ratio of $1: 1: 1$ was pressed into a pellet. The pellet was then put on top of the pressed reactant powders as an igniter. The chemical reaction of the igniter can be initiated at about $260^{\circ} \mathrm{C}$, which results in an instantaneous release of a large amount of heat that ignites the aluminothermic reaction.

The copper mold with the reactants was placed into a reactor as described in the literature [8]. After being purged twice by argon gas, the reactor was heated continuously after introducing $4 \mathrm{MPa}$ argon gas. The reaction of the igniter was started under $4 \mathrm{MPa}$ argon gas when the reactor reached $260^{\circ} \mathrm{C}$. The released heat ignited the aluminothermic reactants and the synthesis reaction was subsequently finished in a few seconds. The products were kept in the reactor under argon gas pressure to cool.

After cooling to room temperature, the products were taken out from the reactor. The obtained gray $\mathrm{Ni}_{65} \mathrm{Al}_{21} \mathrm{Cr}_{14}$ alloy was about $100 \mathrm{~mm}$ in diameter and $8 \mathrm{~mm}$ thick as shown in the photograph in Figure 1. The black $\mathrm{Al}_{2} \mathrm{O}_{3}$ product was on the top of the target product (the density of the alloy is measured to be $7.07 \mathrm{~g} / \mathrm{cm}^{3}$ ), which separated naturally from the desired $\mathrm{Ni}_{65} \mathrm{Al}_{21} \mathrm{Cr}_{14}$ alloy and was removed easily by hand.

The polished cross section of the $\mathrm{Ni}_{65} \mathrm{Al}_{21} \mathrm{Cr}_{14}$ alloy was examined with X-ray diffractometry (XRD, Philips, X' Pert$\mathrm{MRD}$ ) using a $\mathrm{Cu} \mathrm{K} \alpha$ radiation source. The scanning electron microscope (SEM, JSM-5600LV) and field emission SEM
(JSM-6701F) were used for microstructure observation from the cross sections of the $\mathrm{Ni}_{65} \mathrm{Al}_{21} \mathrm{Cr}_{14}$ sample. Thin foils for TEM observation were prepared by twin-jet polishing using a solution of $20 \mathrm{ml}$ sulphuric acid and $80 \mathrm{ml}$ ethanol at a voltage of $60 \mathrm{~V}$ and were examined by using a transmission electron microscope (TEM, JEM-1200EX) operated at $120 \mathrm{KV}$.

The samples for compression test were machined into cylindrical bars with dimensions of $\Phi 3 \mathrm{~mm} \times 5 \mathrm{~mm}$, and the surfaces were polished with 1000-grit emery paper. Quasistatic compression tests at a strain rate of $3 \times 10^{-4} \mathrm{~s}^{-1}$ were conducted at room temperature on a universal tester (Adamel, French). To minimize friction effect, the specimendie interfaces were lubricated with graphite. Vickers microhardness of the $\mathrm{Ni}_{65} \mathrm{Al}_{21} \mathrm{Cr}_{14}$ sample was measured using an MH-5 microhardness tester under a load of $300 \mathrm{~g}$ and a dwell time of $10 \mathrm{~s}$. The sample density was measured by Archimedes method using a balance with a sensitivity of $0.1 \mathrm{mg}$.

\section{Results and Discussion}

The chemical reaction of the igniter is initiated at about $260^{\circ} \mathrm{C}$ and instantaneously releases large heat, which ignites the reaction of the reactants. Then combustion wave of the reaction propagates from top to bottom of the reactant compact and the reactants transform to Ni-Al-Cr alloy and $\mathrm{Al}_{2} \mathrm{O}_{3}$ melt where the combustion wave has passed. The adiabatic temperature $\left(T_{\mathrm{ad}}\right)$ of the combustion reaction at $260^{\circ} \mathrm{C}$ is approximately calculated to be about $2700^{\circ} \mathrm{C}$ by the method as described in the literature $[8,24]$. The products of the $\mathrm{Ni}_{65} \mathrm{Al}_{21} \mathrm{Cr}_{14}$ and $\mathrm{Al}_{2} \mathrm{O}_{3}$ are in superheat liquid state but nearly do not vaporize during the processing because their boiling point rises to above $4500^{\circ} \mathrm{C}$ under the $4 \mathrm{MPa}$ gas pressure by calculation based on the ClausiusClapeyron equation and Trouton rule as described in supporting information of the literature [8]. Since liquid $\mathrm{Al}_{2} \mathrm{O}_{3}$ is immiscible with liquid $\mathrm{Ni}_{65} \mathrm{Al}_{21} \mathrm{Cr}_{14}$, it separates automatically and lifts to the top owing to its low density [8]. The liquid $\mathrm{Ni}_{65} \mathrm{Al}_{21} \mathrm{Cr}_{14}$ is deposited on the copper substrate surface.

Figure 2(a) shows a typical X-ray diffraction pattern of the $\mathrm{Ni}_{65} \mathrm{Al}_{21} \mathrm{Cr}_{14}$ alloy, which indicates that the alloy consists of $\gamma^{\prime}-\mathrm{Ni}_{3} \mathrm{Al}$ and $\gamma-\mathrm{Ni}(\mathrm{Al}, \mathrm{Cr})$ solid solution phases and the crystallographic structures of the alloy have a highly preferred orientation of (200) face. The XRD peaks are significantly broadened, indicating that the alloy has small grain/domain sizes. Scherrer formulation was used to quantitatively analyze the XRD broadenings; the averaged grain size is calculated to be $24.97 \mathrm{~nm}$, and the lattice parameter is calculated to be $0.3550 \mathrm{~nm}$. The contamination phases from igniter $\left(\mathrm{Al}_{2} \mathrm{O}_{3}, \mathrm{MnS}_{\mathrm{x}}\right)$ are mainly dissolved in byproduct $\mathrm{Al}_{2} \mathrm{O}_{3}$ slag and are very small quantity, so they are not detected by XRD test. Although not shown here, the outgrowth black $\mathrm{Al}_{2} \mathrm{O}_{3}$ on top of the $\mathrm{Ni}_{65} \mathrm{Al}_{21} \mathrm{Cr}_{14}$ alloy is mainly composed of $\alpha-\mathrm{Al}_{2} \mathrm{O}_{3}$ phase by the XRD analysis.

The SEM secondary electronic image of the $\mathrm{Ni}_{65} \mathrm{Al}_{21} \mathrm{Cr}_{14}$ alloy is shown in Figure 2(b). It can be seen that the $\mathrm{Ni}_{65} \mathrm{Al}_{21} \mathrm{Cr}_{14}$ alloy is a composite structure of micrometer 


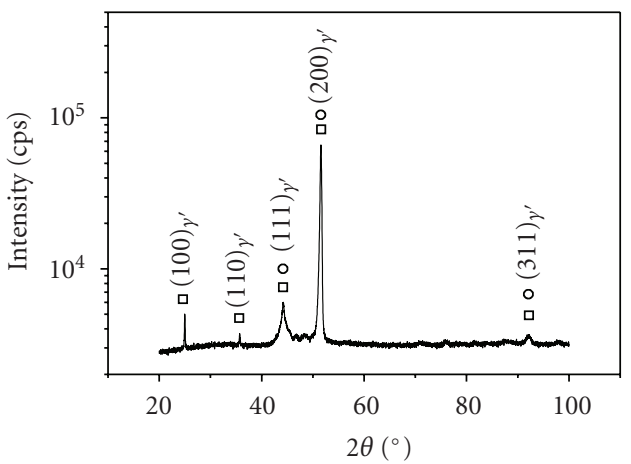

- $\mathrm{Ni}_{3} \mathrm{Al}$ - $\mathrm{Ni}(\mathrm{Al}, \mathrm{Cr})$

(a)

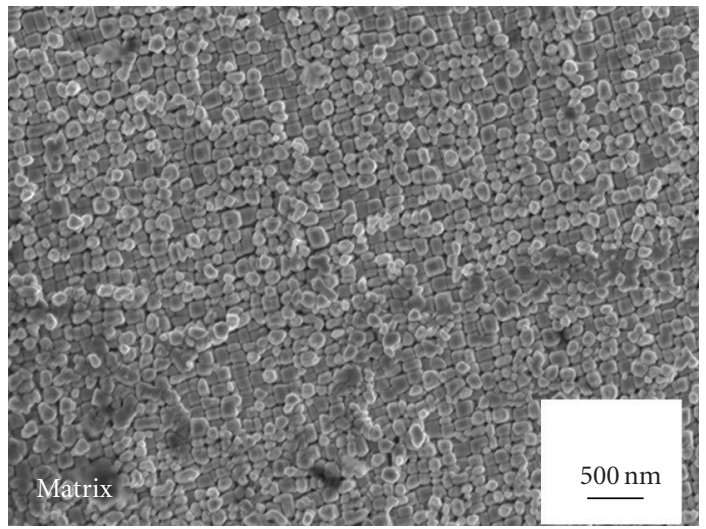

(c)

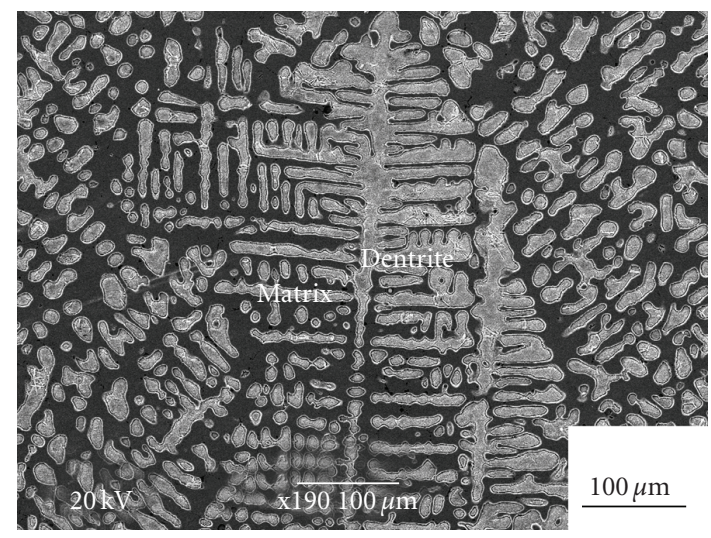

(b)

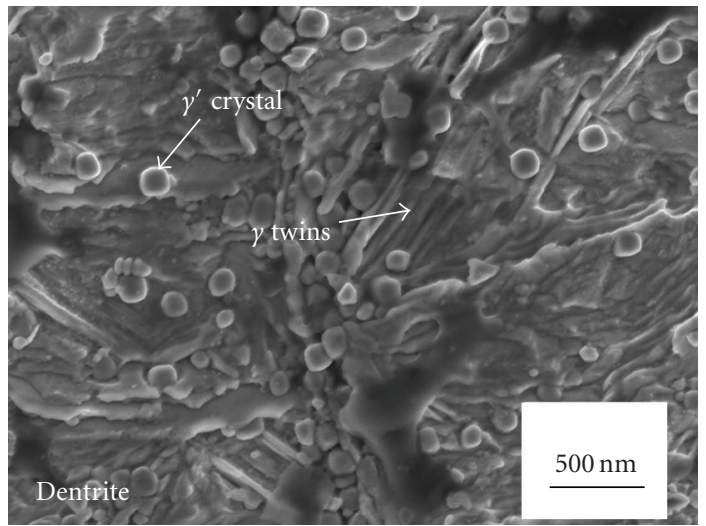

(d)

FIGURE 2: XRD pattern of the $\mathrm{Ni}_{65} \mathrm{Al}_{21} \mathrm{Cr}_{14}$ alloy (a); SEM secondary electron image of the $\mathrm{Ni}_{65} \mathrm{Al}_{21} \mathrm{Cr}_{14}$ alloy (b) and FSEM secondary electron images of the matrix (c) and the dentrite (d).

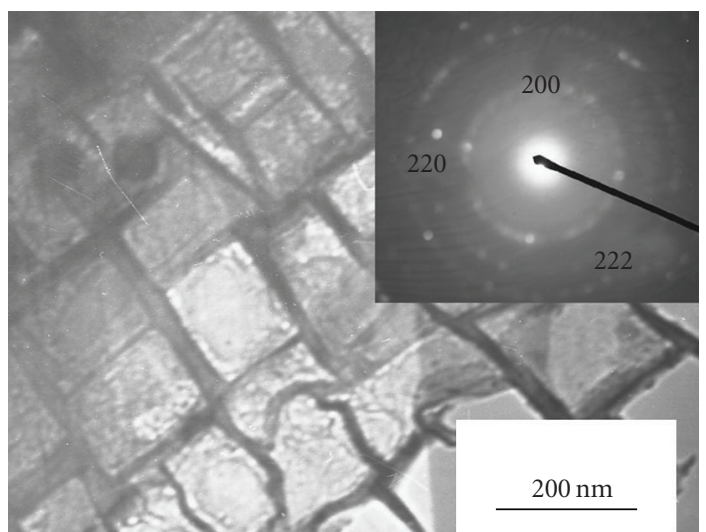

(a)

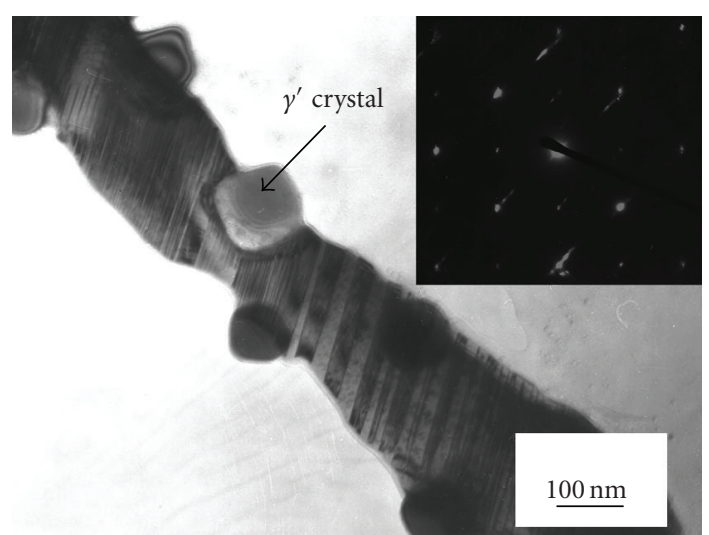

(b)

FIGURE 3: Bright field TEM images of the matrix (a) and dentrite (b) and corresponding SAED patterns.

scaled dendrites dispersed in a matrix. The dendrite occupies about $50 \%$ in volume according to the statistic of the SEM observations. Figures 2(c) and 2(d) show the fine microstructures of the matrix and dendrite by the FESEM secondary electronic images, respectively. It can be seen that the matrix is composed of $80-150 \mathrm{~nm}$ cubic $\gamma^{\prime}$ precipitated phase and
2-5 $\mathrm{nm}$ boundary $\gamma$ phase (Figure 2(c)). The dendrites consist mainly of 50-100 nm lamellar or fiber $\gamma$ phase and a minor cubic $\gamma^{\prime}$ phase (Figure 2(d)). The bright field TEM images of the matrix and dendrites and corresponding selected area diffraction patterns (SAED) are presented in Figure 3. Figure 3(a) indicates that the matrix is composed of 


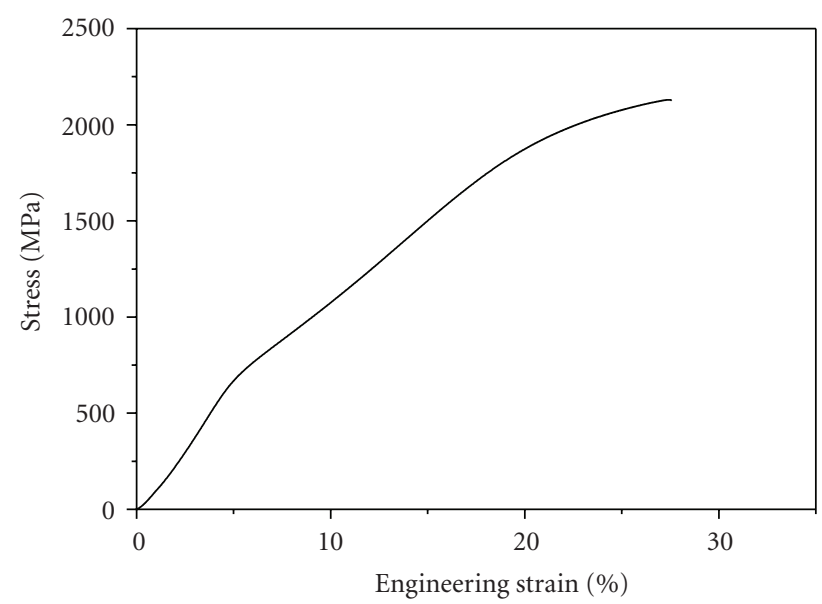

(a)

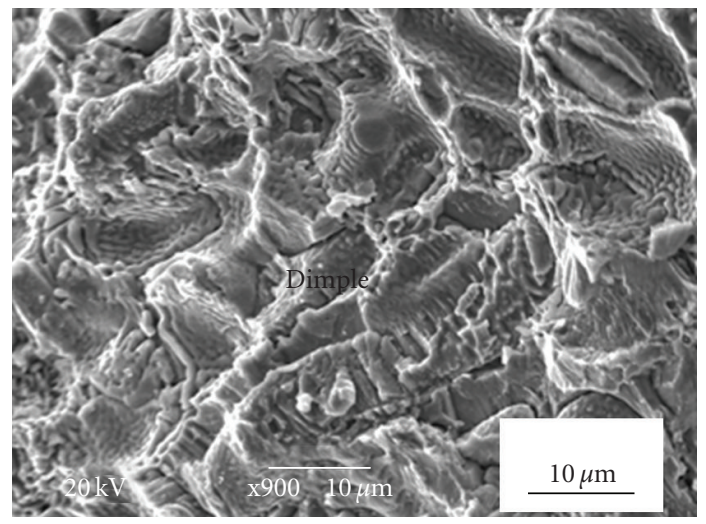

(b)

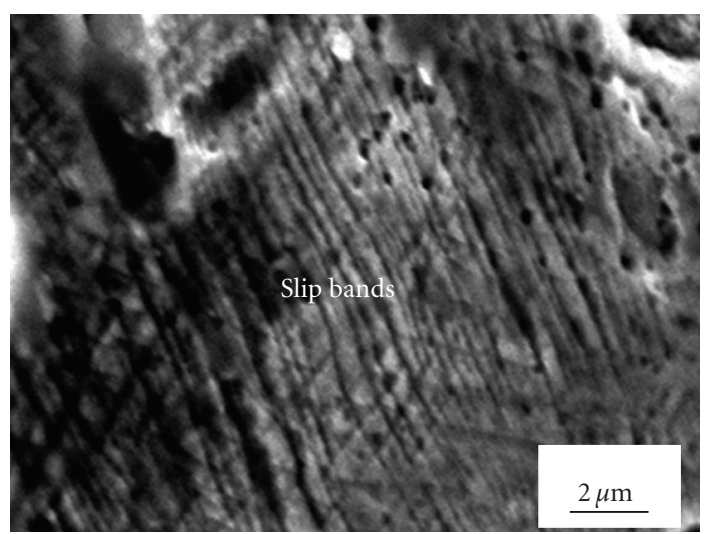

(c)

FIGURE 4: Typical compressive engineering stress—-strain curve (a), SEM micrographs of the fractured surface (b), and fractured profile (c) of the $\mathrm{Ni}_{65} \mathrm{Al}_{21} \mathrm{Cr}_{14}$ alloy.

roughly $80-150 \mathrm{~nm}$ cubic crystallites and $2-5 \mathrm{~nm}$ boundary $\gamma$ phase, which are in good agreement with the result of FESEM. The corresponding SAED pattern shows discontinuous rings, indicating that many different orientations among the grains. By TEM images and corresponding SAED patterns, it can be further found that the nanolamellar and fiber in the dendrites consist of about 3-20 nm high dense twins (see Figure 3(b)). It has been proved that both nano/ultrafine eutectic structure [9, 25-27] and nanotwinned structure $[28,29]$ could enhance strength and ductility of metallic materials.

The formation of the special composite nanostructure is attributed to three factors [30]. First, the contaminants $\left(\mathrm{Al}_{2} \mathrm{O}_{3}, \mathrm{MnS}_{\mathrm{x}}\right.$, etc. $)$ introduced from reactants and igniter dissolve in the metallic melt under the very high degree of superheating $\left(T_{\mathrm{ad}}=2700^{\circ} \mathrm{C}\right)$, and hence there are no heterogeneous nucleation sites available for liquid to crystallize on. Metallic liquid without nucleation sites for crystallization has a high undercooling degree and low crystallization onset temperature for solidification, which results in a large number of small homogeneous nuclei being simultaneously formed during solidification; Second, owing to the high viscosity of the metallic liquid at low crystallization onset temperature, the nuclei growth determined by diffusion of $\mathrm{Ni}, \mathrm{Al}$, and $\mathrm{Cr}$ atoms is slow. Third, the time of nuclei growth is short because of the high cooling rate resulting from the copper substrate quenching.

Figure 4(a) shows a typical compressive engineering stress-strain curve of the nanostructured $\mathrm{Ni}_{65} \mathrm{Al}_{21} \mathrm{Cr}_{14}$ alloy. The yield strength is about $750 \mathrm{MPa}$, which is comparable to a nickel-based superalloy [31]. Impressive fracture strength of $2200 \mathrm{MPa}$ and plastic strain of $26 \%$ was reached in compression test, respectively. The nanostructured $\mathrm{Ni}_{65} \mathrm{Al}_{21} \mathrm{Cr}_{14}$ alloy exhibits a continuous stress increase with increasing strain, indicating continuous strain hardening until failure. Figure 4(b) shows lots of dimples with a diameter of 10$20 \mu \mathrm{m}$ in the fracture surface from the compression test. Although large numbers of slip bands were observed in the fractured profile surface (Figure 4(c)), the local deformation may be impeded by the dendrites which means local stress concentration in compressive deformation [32], which can explain the high strain hardening ability of the nanostructured $\mathrm{Ni}_{65} \mathrm{Al}_{21} \mathrm{Cr}_{14}$ alloy. On the other hand, nanotwin boundaries are much more stable against migration than conventional grain boundaries $[28,29]$. Twin strengthening has been obtained in the nanostructured $\mathrm{Ni}_{65} \mathrm{Al}_{21} \mathrm{Cr}_{14}$ alloy. 
So, in our experiment the nanostructure with dendrites composite and high density nanotwins is responsible for high fracture stress and good ductility in the compression test.

\section{Conclusion}

The large bulk nanostructured $\mathrm{Ni}_{65} \mathrm{Al}_{21} \mathrm{Cr}_{14}$ alloy is obtained by using combustion synthesis technique associated with rapid solidification. The nanostructured $\mathrm{Ni}_{65} \mathrm{Al}_{21} \mathrm{Cr}_{14}$ alloy samples are characterized by SEM, XRD, and TEM. The as-produced large bulk nanostructured $\mathrm{Ni}_{65} \mathrm{Al}_{21} \mathrm{Cr}_{14}$ alloy exhibits simultaneously high compressive fracture strength $(2200 \mathrm{MPa})$ and good ductility $(\sim 26 \%)$.

\section{Acknowledgments}

This work was supported by the National Natural Science Foundation of China (50801064) and the National 973 Project of China (2007CB607601).

\section{References}

[1] K. S. Kumar, H. Van Swygenhoven, and S. Suresh, "Mechanical behavior of nanocrystalline metals and alloys," Acta Materialia, vol. 51, no. 19, pp. 5743-5774, 2003.

[2] M. A. Meyers, A. Mishra, and D. J. Benson, "Mechanical properties of nanocrystalline materials," Progress in Materials Science, vol. 51, no. 4, pp. 427-556, 2006.

[3] Y. Wang, M. Chen, F. Zhou, and E. Ma, "High tensile ductility in a nanostructured metal," Nature, vol. 419, no. 6910, pp. 912-915, 2002.

[4] E. Hosseini and M. Kazeminezhad, "Nanostructure and mechanical properties of 0-7 strained aluminum by CGP: XRD, TEM and tensile test," Materials Science and Engineering A, vol. 526, no. 1-2, pp. 219-224, 2009.

[5] Y. S. Yang, J. G. Bae, and C. G. Park, "Nanostructure and mechanical properties of heavily cold-drawn steel wires," Materials Science and Engineering A, vol. 508, no. 1-2, pp. 148$155,2009$.

[6] N. Tao and K. Lu, "Dynamic plastic deformation (DPD): a novel technique for synthesizing bulk nanostructured metals," Journal of Materials Science and Technology, vol. 23, no. 6, pp. 771-774, 2007.

[7] I. V. Alexandrov and R. Z. Valiev, "Developing of SPD processing and enhanced properties in bulk nanostructured metals," Scripta Materialia, vol. 44, no. 8-9, pp. 1605-1608, 2001.

[8] P. La, J. Yang, D. J. H. Cockayne, W. Liu, Q. Xue, and Y. Li, "Bulk nanocrystalline FeAl-based material prepared by aluminothermic reaction," Advanced Materials, vol. 18, no. 6, pp. 733-737, 2006.

[9] J. Yang, J. Ma, W. Liu, Q. Bi, and Q. Xue, "Large-scale Fe$\mathrm{C}$ nanoeutectic alloy prepared by a self-propagating hightemperature synthesis casting route," Scripta Materialia, vol. 58, no. 12, pp. 1074-1077, 2008.

[10] L. Li, Q. Bi, J. Yang et al., "Large-scale synthesis of Al-Cu-Fe submicron quasicrystals," Scripta Materialia, vol. 59, no. 6, pp. 587-590, 2008.

[11] L. Fu, J. Yang, Q. Bi, and W. Liu, "Enhanced ductility of dendrite-ultrafine eutectic composite $\mathrm{FeB}$ alloy prepared by a self-propagating high-temperature synthesis," Advanced Engineering Materials, vol. 11, no. 3, pp. 194-197, 2009.
[12] J. Yang, P. La, W. Liu, and Y. Hao, "Microstructure and properties of $\mathrm{Fe}_{3} \mathrm{Al}-\mathrm{Fe}_{3} \mathrm{AlC}_{0.5}$ composites prepared by self-propagating high temperature synthesis casting," Materials Science and Engineering A, vol. 382, no. 1-2, pp. 8-14, 2004.

[13] P. La, Y. Wei, R. Lv, Y. Zhao, and Y. Yang, "Effect of Mn element on microstructure and mechanical properties of bulk nanocrystalline $\mathrm{Fe}_{3} \mathrm{Al}$ based materials prepared by aluminothermic reaction," Materials Science and Engineering A, vol. 527, no. 9, pp. 2313-2319, 2010.

[14] H. Hou, Y. Zhao, and Y. Zhao, "Simulation of the precipitation process of ordered intermetallic compounds in binary and ternary Ni-Al-based alloys by the phase-field model," Materials Science and Engineering A, vol. 499, no. 1-2, pp. 204-207, 2009.

[15] P. Peng, D. W. Zhou, J. S. Liu, R. Yang, and Z. Q. Hu, "Firstprinciples study of the properties of $\mathrm{Ni} / \mathrm{NiAl}$ interface doped with B or P," Materials Science and Engineering A, vol. 416, no. 1-2, pp. 169-175, 2006.

[16] J. Bonneville and C. Coupeau, "Quantitative atomic force microscopy analysis of slip traces in $\mathrm{Ni}_{3} \mathrm{Al}$ yield stress anomaly," Materials Science and Engineering A, vol. 483-484, pp. 87-90, 2008.

[17] Y. Ma and A. J. Ardell, "Chemical diffusion in hypostoichiometric $\mathrm{Ni}_{3} \mathrm{Al}$ from data on coarsening of $\mathrm{Ni}-\mathrm{Al}$ solid solution precipitates," Materials Science and Engineering A, vol. 516, no. 1-2, pp. 259-262, 2009.

[18] L. N. Wang, Y. Liu, J. J. Yu et al., "Orientation and temperature dependence of yielding and deformation behavior of a nickel-base single crystal superalloy," Materials Science and Engineering A, vol. 505, no. 1-2, pp. 144-150, 2009.

[19] A. Hibino, S. Matsuoka, and M. Kiuchi, "Synthesis and sintering of $\mathrm{Ni}_{3} \mathrm{Al}$ intermetallic compound by combustion synthesis process," Journal of Materials Processing Technology, vol. 112, no. 1, pp. 127-135, 2001.

[20] L. Y. Sheng, W. Zhang, J. T. Guo et al., "Microstructure and mechanical properties of $\mathrm{Ni}_{3} \mathrm{Al}$ fabricated by thermal explosion and hot extrusion," Intermetallics, vol. 17, no. 7, pp. 572-577, 2009.

[21] N. S. Stoloff, "Physical and mechanical metallurgy of $\mathrm{Ni}_{3} \mathrm{Al}$ and its alloys," International Materials Reviews, vol. 34, no. 4, pp. 153-183, 1989.

[22] H. Choe and D. C. Dunand, "Synthesis, structure, and mechanical properties of $\mathrm{Ni}-\mathrm{Al}$ and $\mathrm{Ni}-\mathrm{Cr}-\mathrm{Al}$ superalloy foams," Acta Materialia, vol. 52, no. 5, pp. 1283-1295, 2004.

[23] T. Czeppe and S. Wierzbinski, "Structure and mechanical properties of $\mathrm{NiAl}$ and $\mathrm{Ni}_{3} \mathrm{Al}$-based alloys," International Journal of Mechanical Sciences, vol. 42, no. 8, pp. 1499-1518, 2000.

[24] J. Ma, J. Yang, Q. Bi, and W. Liu, "Preparation of an ultrafinegrained Fe-40Al intermetallic compound," Acta Metallurgica Sinica (English Letters), vol. 23, no. 1, pp. 50-56, 2010.

[25] J. Das, R. Theissmann, W. Löser, and J. Eckert, "Effect of Sn on microstructure and mechanical properties of Ti-Fe- $(\mathrm{Sn})$ ultrafine eutectic composites," Journal of Materials Research, vol. 25, pp. 943-956, 2010.

[26] J. Eckert, J. Das, G. He, M. Calin, and K. B. Kim, “Ti-base bulk nanostructure-dendrite composites: microstructure and deformation," Materials Science and Engineering A, vol. 448451, pp. 24-29, 2007.

[27] K. B. Kim, J. Das, W. Löser et al., "Microstructural comparison of $\mathrm{ZrNbCuNiAl}$ nanostructure-dendrite composites produced by different casting techniques," Materials Science and Engineering $A$, vol. 448-451, pp. 747-751, 2007. 
[28] L. Lu, X. Chen, X. Huang, and K. Lu, "Revealing the maximum strength in nanotwinned copper," Science, vol. 323, no. 5914, pp. 607-610, 2009.

[29] L. Lu, Y. Shen, X. Chen, L. Qian, and K. Lu, "Ultrahigh strength and high electrical conductivity in copper," Science, vol. 304, no. 5669, pp. 422-426, 2004.

[30] H. Hu, Metal Solidification Principle, China Machine Press, Beijing, China, 2000.

[31] G. Mi, Z. Li, S. Tian et al., "Microstructure and tensile properties of spray-deposited IC6 alloy," Journal of Materials Science and Technology, vol. 14, no. 2, pp. 143-146, 1998.

[32] H. S. Kim and Y. Estrin, "Strength and strain hardening of nanocrystalline materials," Materials Science and Engineering A, vol. 483-484, pp. 127-130, 2008. 

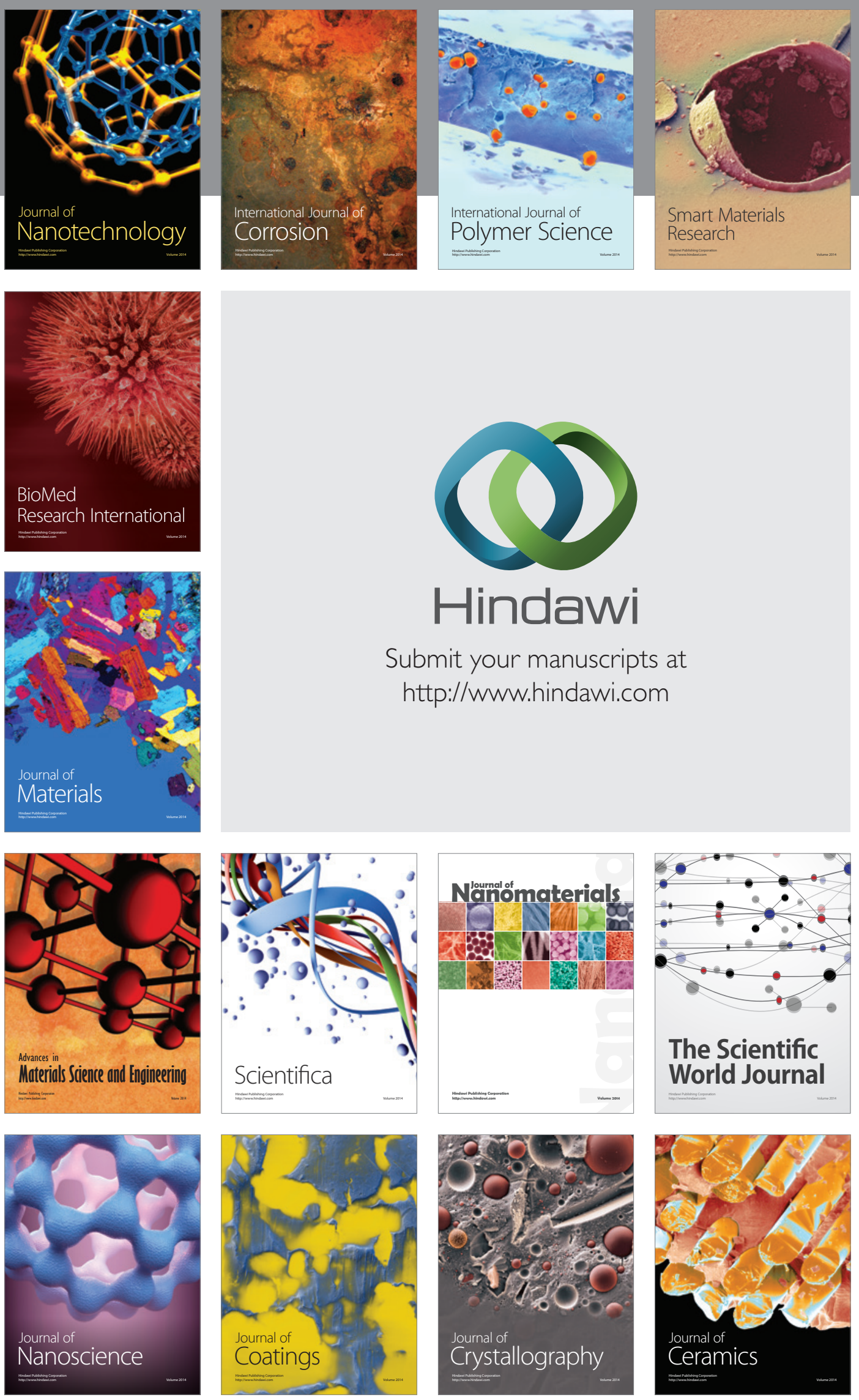

The Scientific World Journal

Submit your manuscripts at

http://www.hindawi.com

\section{World Journal}

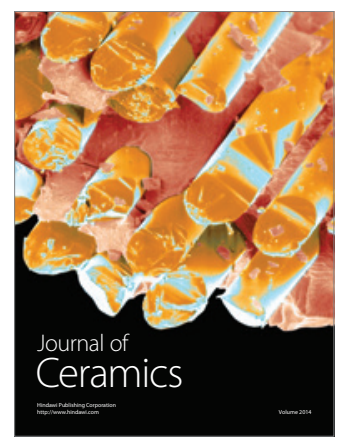

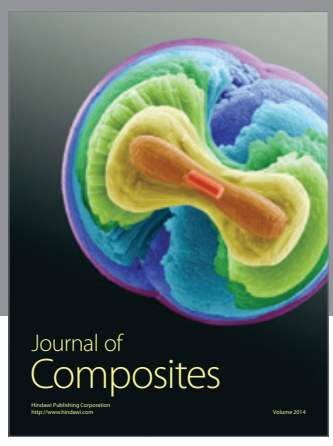
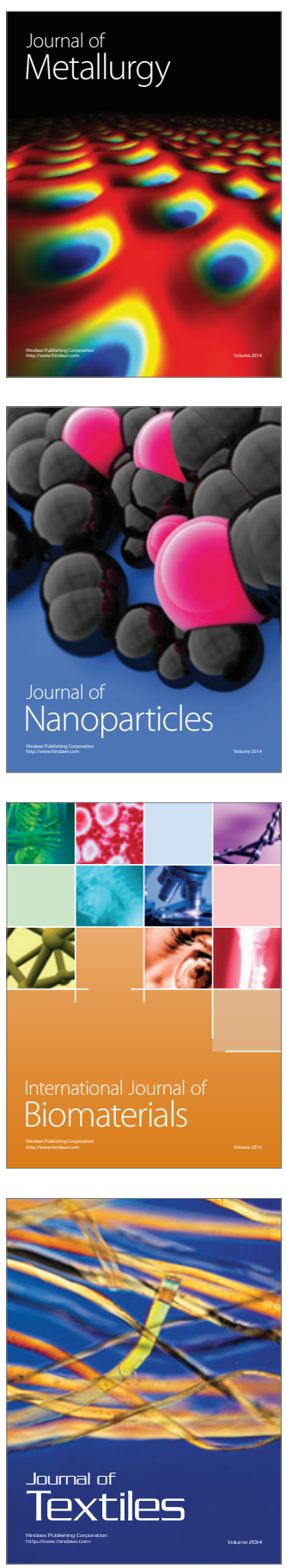